\title{
Fava bean-induced hemolytic crisis in glucose-6-phosphate dehydrogenase deficiency
}

\author{
IPG Karyana, MD; IB Mudita, MD
}

G lucose-6-Phosphate Dehydrogenase (G6PD) deficiency is a hereditary hemolytic anemia, inherited as an Xlinked disorders, affects about 400 million peoples worldwide. This disease is highly polymorphic with more than 300 reported variants. ${ }^{1-3}$ The typical symptoms during acute episodes of hemolysis are fatigue, shortness of breath, pale or yellowish skin, quick pulse, brown reddish urine and enlarged spleen. ${ }^{2,4}$ G6PD enzyme is needed in the Hexose Monophosphate Pathway (HMP), in which the result of this metabolism protects the red blood cell membrane against oxidative stress. In G6PD deficiency, the oxidative agent can cause the red blood cell membrane unstable, and will result in hemolytic process. ${ }^{1,5}$

Most of the patients with severe G6PD deficiency and chronic hemolytic anemia are from Northern Europe. ${ }^{1,5}$ Migration has contributed to the worldwide distribution of G6PD deficiency, which is particularly clustered in the Mediterranean littoral, in Africa and the Far East. The frequency of G6PD deficiency varies in males of different ethnic groups. In Chinese, it is about 5\%, in Black America $10 \%$ to $15 \%$ and in Kurdi Jews as high as $70 \%$. Severe and partial deficiencies are detected in $4.3 \%$ of male and $1.9 \%$ of female. In Indonesia, the disease is very rare.

This paper reports a case of hemolytic crisis due to fava beans in a child with G6PD deficiency.

\section{The Case}

A 2-year old Balinese boy was admitted to the Department of Child Health, Sanglah Hospital on December 3, 2001 with a chief complaint of yellowish skin. He was referred by a general practitioner. The yellowish skin appeared since one day before admitted to Sanglah Hospital. It initiated slightly, then spread all over his body. Two days before hospitalization, he consumed two small sacks of fava beans. He took fava beans for the first time. He had neither fever, nausea, vomiting nor bleeding. The urine was brown reddish color appearance since two hours before admission with normal frequency and volume. The color of the stool was yellow, without blood, no mucous and no fat. No history of family with the same disease was found. The immunization status was complete related by the age. The growth chart of the patient showed normal growth with no developmental disorders.

The history of delivery showed that he was born spontaneously at Sanglah Hospital, cried spontaneously, with birth weight of 3000 grams and gestational age of 9 months. On the 2nd day of life, he

From the Department of Child Health, Medical School, Udayana University, Denpasar.

Reprint Requests to: IPG Karyana, Department of Child Health, Udayana University, Sanglah Hospital, Denpasar, Indonesia. Tel. 62-61-227911/15 Ext. 117 \& 128, Fax. 62-61-244038 
got jaundice and phototherapy was given. No history of exchange transfusion. Maternal history of consuming oxidative agents was denied.

On physical examination, the baby was jaundice and irritable, the pulse rate was 110/minute, respiration rate 32 /minute, axillary temperature $37^{\circ} \mathrm{C}$ and the body weight $8.8 \mathrm{~kg}$. The head looked normocephalic and the fontanella was closed. The conjunctivae was pale and the sclera was icteric; no nystagmus, strabismus and deviation of conjugation. The pupil was isochoric and the reflexes were positive. Ears, nose, and throat were normal. The neck was normal and no enlargement of lymph nodes. The chest was symmetrical, the breath sounds were vesicular, no rales and wheezing. On auscultation, the heart sounds were normal. On abdomen examination, we found normal bowel sound, liver and spleen were not enlarged. The limbs were pale and jaundice. The skin all over the body looked icteric.

The laboratory finding revealed leukocytes count was 13,500/uL, hemoglobin level $4.6 \mathrm{~g} / \mathrm{dL}$, PCV 13.9\%, MCV $83 \mathrm{fL}, \mathrm{MCHC} 33.1 \mathrm{~g} / \mathrm{dL}$ and platelet count 400,000/uL, total bilirubin level $5.88 \mathrm{mg} /$ $\mathrm{dL}$, indirect bilirubin level $0.81 \mathrm{mg} / \mathrm{dL}$, and reticulocytes count was $5.4 \%$.

Based on the history, clinical manifestation and laboratory findings, our working diagnosis was hemolytic crisis suspected due to G6PD deficiency with fava beans as the inducer, with the differential diagnosis of Autoimmune Hemolytic Anemia (AIHA).

The patient was treated with oxygen 2 liters/ minute and red blood cell transfusion $260 \mathrm{cc}$ to reach hemoglobin level of $12 \mathrm{~g} / \mathrm{dL}$. Diet of $900 \mathrm{Kcal} /$ day was given. Fava beans and the other oxidative agents were avoided.

G6PD level of the patient, the father and the mother were $50 \mathrm{IU} / \mathrm{g} \mathrm{Hb}, 40 \mathrm{IU} / \mathrm{gHb}$, and $120 \mathrm{IU} / \mathrm{g}$ $\mathrm{Hb}$ respectively (normal limits : 118-144 IU/g Hb). The direct and indirect Coombs Test were negative; peripheral blood smear showed polychromatic, poikilocytosis, and anisocytosis; Heinz bodies was positive. Urinalysis showed the presence of bilirubin and hemoglobin in the urine. Serum creatinine and urea level were normal, while haptoglobin level was $12 \mathrm{mg} / \mathrm{dL}(<25 \mathrm{mg} / \mathrm{dL}$ was a predictor of hemolysis).
Four days later jaundice and pale disappeared. The post-transfusion laboratory examination revealed hemoglobin level of $11.5 \mathrm{~g} / \mathrm{dL}$.

Based on the result of laboratory examination, the final diagnosis was hemolytic crisis suspected due to G6PD deficiency induced by fava beans.

\section{Discussion}

G6PD deficiency is a hereditary disease with worldwide distribution. Since this condition was Xlinked inherited, the male genotype is G6PD deficient hemizygote $\left(\mathrm{X}^{*} \mathrm{Y}\right)$, but the genotype in female may be homozygote $\left(\mathrm{X}^{*} \mathrm{X}^{*}\right)$ or heterozygote $\left(\mathrm{X}^{*} \mathrm{X}\right)$. Male hemizygote and female homozygote are more severely affected than female heterozygote. Some female heterozygote have a quantitative deficiency as severe as hemizygote. ${ }^{1,2}$ Our patient is male with G6PD level lower than normal. So the genotype should be G6PD deficiency hemizygote. While his mother had a low G6PD level, the genotype may be homozygote or heterozygote. Genetic testing is needed to know his mother genotype.

G6PD enzyme is an essential enzyme needed for stabilization of the red blood cell (RBC), being the first enzyme in the cascade that catalyses production of glutathion reductase and glutathion peroxides to protect the RBC against damage from oxidative stress. The cascade is crippled in the absence of G6PD enzyme. ${ }^{3}$ Certain drugs and substances in sufficient quantities can seriously injure the RBC. It then becomes important for the caretaker to avoid certain medications, including antimalarials (primaquine, pamaquine, chloroquine), analgesics (aspirin, phenacitine, aceteniliamid), antibacterials (sulfonamides, dapsone, nitrofurantoin, chloramphenicol, ciprofloxacin, nalidixic acid, furazolidine), certain food such as fava beans and also to avoid infection. In our case, fava beans was suspected to be the trigger factor of hemolytic crisis. We have to note that fava beans is a potent oxidative agent, since the hemolytic crisis may develop not only by ingestion of fava beans directly but can also be transmitted through breast-feeding or even in utero by maternal ingestion of such agent. $^{5}$

The acute and severe hemolytic syndrome due to fava beans is called Favism. Favism is similar to 
drug-induced hemolysis. Case of hemolytic crisis due to fava beans in children with G6PD deficiency was rare. Similar case was also reported in Nepal. ${ }^{5}$ In Indonesia, the incidence of fava bean-induced hemolytic crisis was not known.

Based on activity levels, G6PD deficiency were classified, as enzyme deficiency with chronic non spherocytic hemolytic anemia, severe enzyme deficiency $(<10 \%)$, moderate to mild enzyme deficiency (10-60\%), very mild to no enzyme deficiency (>6\%) and increased enzyme activity. ${ }^{1,3}$

In our case, the G6PD enzyme level was $50 \mathrm{IU} / \mathrm{g}$ $\mathrm{Hb}$, which was categorized in moderate to mild enzyme deficiency. How does the moderate to mild deficiency of G6PD can cause hemolytic crisis in this case was unclear. It was probably due to the fact that fava beans is a potential oxidative agent.

In G6PD deficiency, acute hemolysis occurs after 1 to 3 days post-exposure to oxidative agent. The hemoglobin level drops significantly. The hematocrit drops $25 \%$ to $35 \%$, reaching its nadir at 8 to 10 days. ${ }^{4}$ Heinz bodies are present in peripheral blood smear. Methemalbuminemia, hemoglobinemia, hemoglobinuria, decreased haptoglobin and GSH level, GSH instability, and bizarre red cell morphology with polychromasia, bite-cells, schistocytes, and cell resembling half moon are noted. 3,6 Patient may have malaise, low-grade fever, icteric sclera, abdominal pain and dark urine. Hepatosplenomegaly may occur but is unusual. Haptoglobin can be used as an indicator of the presence of intravascular hemolysis. If haptoglobin decrease lower than $25 \mathrm{mg} / \mathrm{dL}$, it means that severe intravascular hemolysis occurs. ${ }^{1,4}$ In the equilibrium phase, the patients have complete compensated hemolytic anemia process without anemia, reticulocytosis or jaundice. ${ }^{7,8}$ In our case, the sign of hemolysis occurred one day after consuming fava beans, shown by slight jaundice. The laboratory findings revealed severe anemia with hematocrit of $13.5 \%$, total bilirubin increased more than normal, and a decreased haptoglobin level lower than $25 \mathrm{mg} / \mathrm{dL}$ In peripheral blood smear the erythrocyte revealed polychromatic, poikilocytosis, and anisocytosis. Heinz bodies were also positive. The urinalysis showed bilirubinuria and hemoglobinuria. We did not find fever, abdominal pain, and hepatosplenomegaly.

There is no specific treatment for G6PD deficiency. Patients with G6PD deficiency should avoid the exposure to drugs and other toxic agents known to induce hemolysis. Infection can cause hemolysis as well and should be treated appropriately. The general principle of care, including exchange transfusion for neonatal hyperbilirubinemia and RBC transfusion for hemolytic crisis. ${ }^{1,2,9}$ In neonates with G6PD deficiency, Sn Mesoporphyrin can be used to control hyperbilirubinemia. ${ }^{9}$ The function of Sn Mesoporphyrin is inhibiting the bilirubin production. ${ }^{9,10}$ In our case, the patient suffered from severe anemia. The prognosis is good, since there was no complication found and had been immediately resolved.

\section{Summary}

A case of acute hemolytic crisis suspected due to fava beans in a 2 year-old Balinese boy with G6PD deficiency was reported. The diagnosis was established based on clinical features and laboratory investigation. He had a good clinical condition after he had got RBC transfusions. The patient prognosis was good, since there was no any complications found and the hemolysis was immediately resolved.

\section{References}

1. Denis R. Miller. Hemolytic anemias: metabolic defects. In: Denis R. Miller, Robert L. Baehner, editors. Blood disease of infancy and childhood. $7^{\text {th }}$ ed. St. Louis: Mosby-Year Book; 1995. p. 273-384.

2. Michael Kaplan, Ernest Beutler, Hendrik J, Mc Laren DW, Lewison LJ, Brown AK, et al. Neonatal hyperbilirubinemia in glucose 6-phosphate dehydrogenase deficient heterozygotes. Pediatrics 1999;104:68-74.

3. Beutler E. G6PD deficiency. Blood 1994;84:3613-36.

4. Stevenson DK, Vreman HJ. Carbon monoxide and bilirubin production in neonates. Pediatrics 1997;100:252-4.

5. Shrestha SR, Dalzell WAB. Hemolytic crisis in child. JNMA 2001;40:145-6.

6. Slusher TM, Vreman HJ, Mc Laren DW, Beutler E, Renbaum P, Hammerman C, et al. Glucose-6-phosphate dehydrogenase deficiency and carboxyhemoglobin concentrations associated with bilirubin-related morbidity and death in Nigerian infants. J Pediatr 1995; $126: 102-8$ 
IPG Karyana et al: Fava bean-induced hemolytic crisis in G6PD deficiency

7. Kaplan M, Nurit Algur, Hammerman C. Onset of jaundice in glucose-6-phosphate dehydrogenase-deficient. Neonates 2001;108:956-9.

8. Kaplan M, Hammerman C. Glucose-6-Phosphate dehydrogenase-deficient neonates: a potential cause for concern in North America. Pediatrics 2000; 106:1478-9.

9. Timos Valaes, George S. Drummond, Attalah Kappas. Control of Hyper-bilirubinemia in glucose-6- phosphate dehydrogenase-deficient newborn using an inhibitor of bilirubin production, sn mesporphyrin. Pediatrics 1998;101:64-70.

10. Attalah Kappas, George S Drummond, Timos Valaes. A single dose of sn mesoporphyrin prevents development of severe hyperbilirubinemia in glucose-6-phosphate dehydrogenase-deficient newborn. Pediatrics 2001;108:25-30. 